SLAC-TN-14-002

Replaces: SLAC CN-166

\title{
Damping Ring Kickers
}

\author{
By: Fatin Bulos, et. al. \\ SLAC, National Accelerator Laboratory, Stanford, California 94309 USA
}

\begin{abstract}
:
The principle of the design of these magnets was discussed in CN-72. Fig. 1 shows what the total system looks like. Such a system was completed last January and since then we have been evaluating its performance.
\end{abstract}




\section{SINGLE PASS COLLIDER MEMO CN- 16}

\section{AUTHOR: F. Bulos/B. Tomlin/J. Weaver

\section{TITLE: DAMPING RING KICKERS}

The principle of the design of these magnets was discussed in CN-72. F1g. 1 shows what the total system looks like.

Such a system was completed last January and since then we have been evaluating its performance.

To remind the reader:

1) Space available along the beam allows a magnetic length of $33 \mathrm{cms}$ max, while the physical length should not exceed $40 \mathrm{cms}$.

2) Magnetic kick amplitude jitter should be $\leq .03 \% ; 8 \mathrm{mr}$ kick is required at $1.2 \mathrm{GeV}$.

3) Magnetic kick should reach max in $\leq 1 / 2$ ring period, and fall back to zero in $\leq 1 / 2$ ring period. The ring period is $\approx 117 \mathrm{~ns}$.

In order to select the matched impedance of the system, designs were worked out for various impedances. Cable availability dictated that $Z=\frac{50 \Omega}{N}$ where $N$ is an integer. Table I illustrates various designs. An impedance of $16.7 \Omega$ was chosen as the best compromise between thyratron performance and power supply requirements. Also experience with thyratrons and Blumleins indicated that the electrical pulse length should not exceed $40 \mathrm{~ns}$ in order to satisfy the time requirements and allow for filling (transit) time.

\section{System Performance}

(A) PFN: The line performed as expected up to the max voltage of $20 \mathrm{kV}$ available at test time. Fig. 2a shows the pulse obtained at $18 \mathrm{kV}$ with a Pearson transformer of rise time $10 \mathrm{~ns}$, using a 519 scope. Rise time $10-90 \% \approx 15 \mathrm{~ns}$, and flat top $\approx 20$ ns.

The thyratron showed a jitter of $< \pm 1 \mathrm{~ns}$ at $10 \mathrm{kV}$. At $18 \mathrm{kV}$ jitter seems to increase reaching $= \pm 1.0 \mathrm{~ns}$. More accurate measurements are in progresg... Ful1 voltage $(\approx 40 \mathrm{kV})$ jitter should also be measured. 
(B) Magnet: The impedance, transit time, magnetic kick amplitude and times came out as calculated, and as far as duration of magnetic kick we are safe by a few nanoseconds. Fig. $2 b$ shows a typical $\int B d l$ for the magnet.

Preliminary value of the amplitude jitter due to a time jitter of the thyratron of $\pm 1 \mathrm{~ns}$ was estimated at $\approx .1 \%$. This is a difficult measurement to make, and a more precise method to measure stability is being developed by $R$. Larsen group. Originally we aimed at a "flat" top of the magnetic kick of 5 ns to take care of the max jitter expected from a good thyratron. This goal was not achieved. The reason can be understood from $\mathrm{Fig}$. 3a which shows the electric pulse at the beginning and end of the magnet. In travelling through the magnet, the rise time deteriorated more than was expected. This is due mainly to the high frequency response of the ferrite. To achieve a $5 \mathrm{~ns}$ flat top the pulses from beginning and end of the magnet should overlap at their maxima by $5 \mathrm{~ns}$. Fig. 3a shows that they are barely beginning to overlap.

If the more accurate measurement of flatness confirms this picture something has to be done - what?

In anticipation we list all possible approaches in order of preference. These schemes were discussed with various experts at Berkeley, FNL and Livermore. They all agree with the analysis.

1. Find a ferrite with better frequency response. Such a ferrite will have a lower $\mu$ and will require more voltage to generate the required field. For example a $\mu=50$ requires $43 \mathrm{kV}$, a $\mu=25$ requires $\underline{52} \mathrm{kV}$.

2. Lengthen the electric pulse by $5 \mathrm{~ns}$ and shorten the magnet to $\approx 2 / 3$ its present length. This also requires an increase of voltage. For example shortening the magnet to $26 \mathrm{cms}$ requires an increase in effective voltage from $36 \mathrm{kV}$ to $46 \mathrm{kV}$. This reduces transit time by $3.5 \mathrm{~ns}$ and gains a small improvement in rise time. The overall gain in overlap would be $>5 \mathrm{n} . \mathrm{s}$. 
3. Change the impedance of the magnet to $25 \Omega$. This is similar to 2 above except that the ferrite volume is reduced considerably without shortening the magnet. One may also lengthen pulse. Voltage required is $48 \mathrm{kV}$. The gain is $=4 \mathrm{~ns}$ in transit time (Table I), plus whatever improvement results from volume reduction. If magnet is also shortened as in 2 the voltage needed is $61 \mathrm{kV}$.

4. $\mathrm{Z}$ magnet $25 \Omega, \mathrm{Z}$ line $12.5 \Omega$. Divide magnet electrically into two halves feeding each with $2 \times 50 \Omega$ cable. This is harder on the thyratron. Gain is $6 \mathrm{~ns}$ in transit time, $\mathrm{kV}$ needed $\approx 36 \mathrm{kV}$.

Common to all schemes is an increase in power supply voltage. Except for 4 and 2 nd alternative of 3 , the power supply has to increase from its present $25 \mathrm{kV}$ to $30 \mathrm{kV}$. The supplier says it is not difficult. We recommend this be done. Obviously 1. is the easiest. We considered the following ferrites STACKPOLE C12, C14; TOSHIBA M4C21A, M4D21A. Their properties are not as well documented and it is not clear that their slight improvement in frequency response compensates for some of their undesirable features. $\mathrm{Cl} 2$ is probably the best.

Our Ist choice is 2 , 2nd choice is 3 . changing the length and/or impedance of the linac is very easy. Shortening the ferrite is trivial. So let us increase the DC supply voltage to $30 \mathrm{kV}$ which will keep options 1 to 3 open.

It is amusing to contemplate an air transmission line (no ferrite). With the space available to us we need in excess of $600 \mathrm{kV}:$ : This voltage is independant of the impedance of the 1 ine. 
TABLE I

Using $\mu=125, \varepsilon=12.5$, Ferrite thickness $1.91 \mathrm{~cm}$ (The $4 \mathrm{C} 4$ Ferrites we have), $\mathrm{g}=2.25 \times 2.25 \mathrm{~cm}$, Magnetic length $=33 \mathrm{cms}$.

$\begin{array}{lrrrr}Z(\Omega) & 50 & 25 & 16.7 & 12.5 \\ \ell_{f}(\mathrm{~cm}) & 7 & 27 & 55 & 89.5 \\ \mu_{\mathrm{e}} & 4 & 11.8 & 21.3 & 30.9 \\ \varepsilon_{\mathrm{e}} & 9.7 & 11.6 & 12.0 & 12.2 \\ \mathrm{I}(\mathrm{kA}) & 1.77 & 1.92 & 2.12 & 2.37 \\ V(\mathrm{kV}) & 88.5 & 48.0 & 35.5 & 30.0 \\ \tau(\mathrm{ns}) & 6.3 & 11.7 & 16 & 19.5\end{array}$

Where: $\quad \ell_{f}=$ cross-sectional length of ferrite

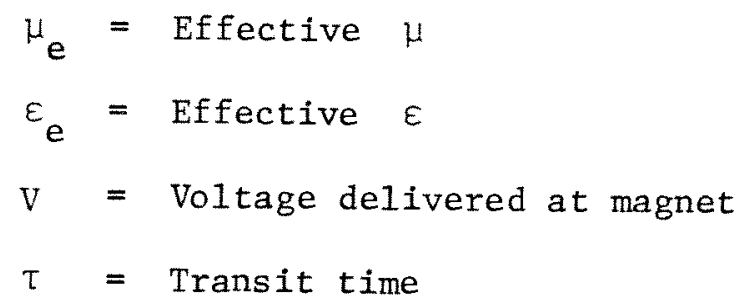


$-$

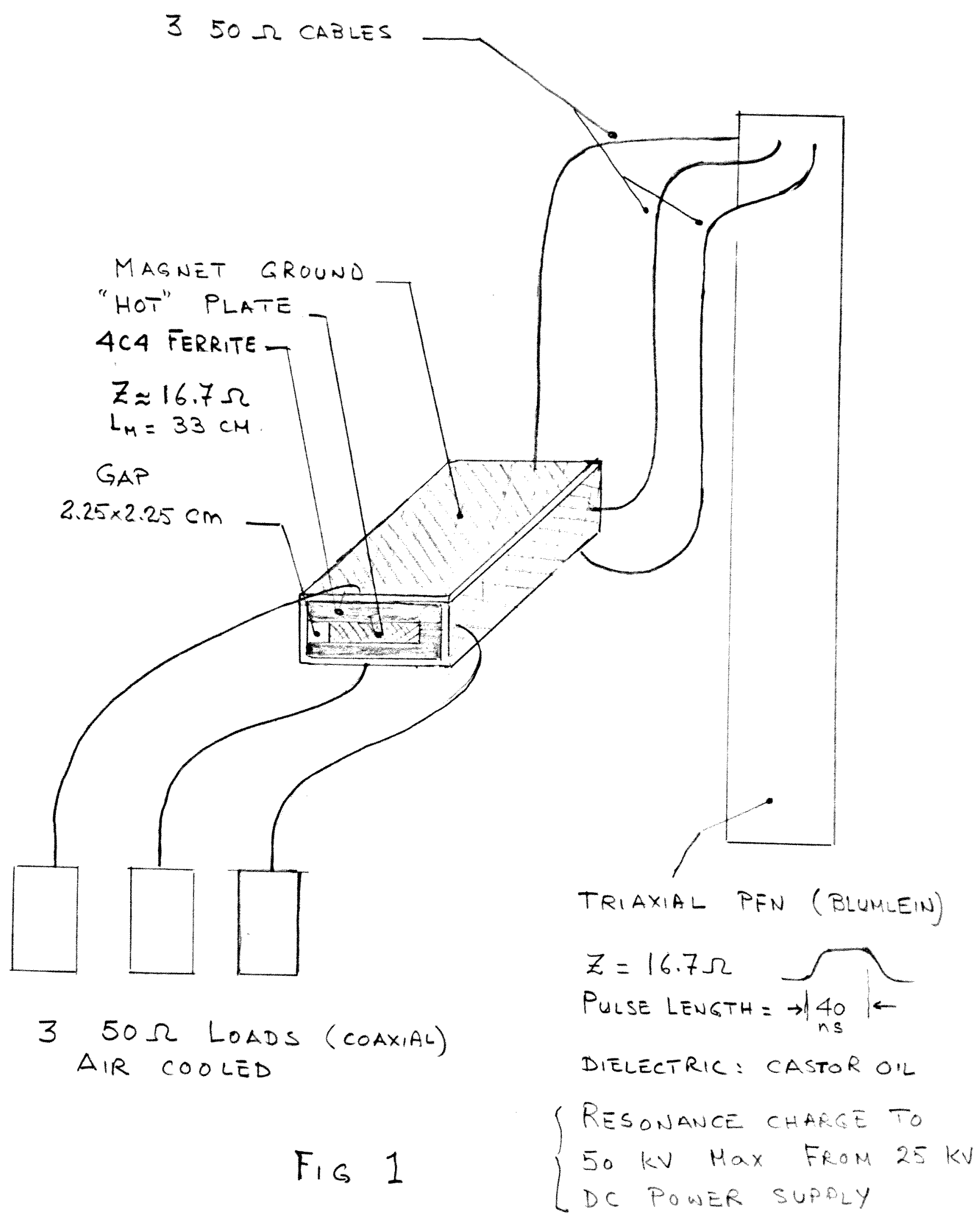



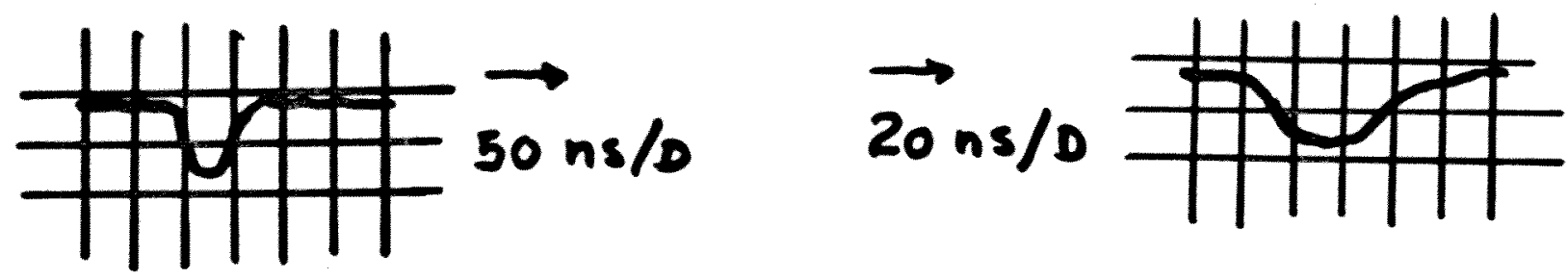

Pulse Ampl. $=18 \mathrm{kV}$

Fig $2 a$

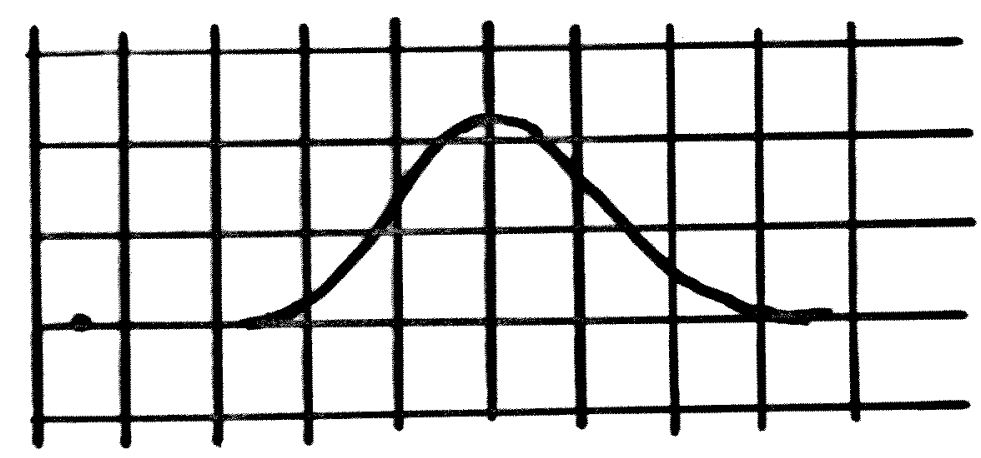

$\rightarrow 20 \mathrm{~ns} / \mathrm{D}$; 1 ARBITRARY

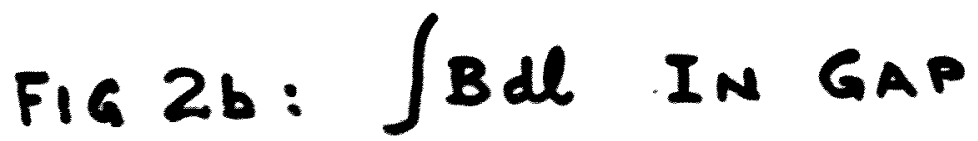


11

$-7-$
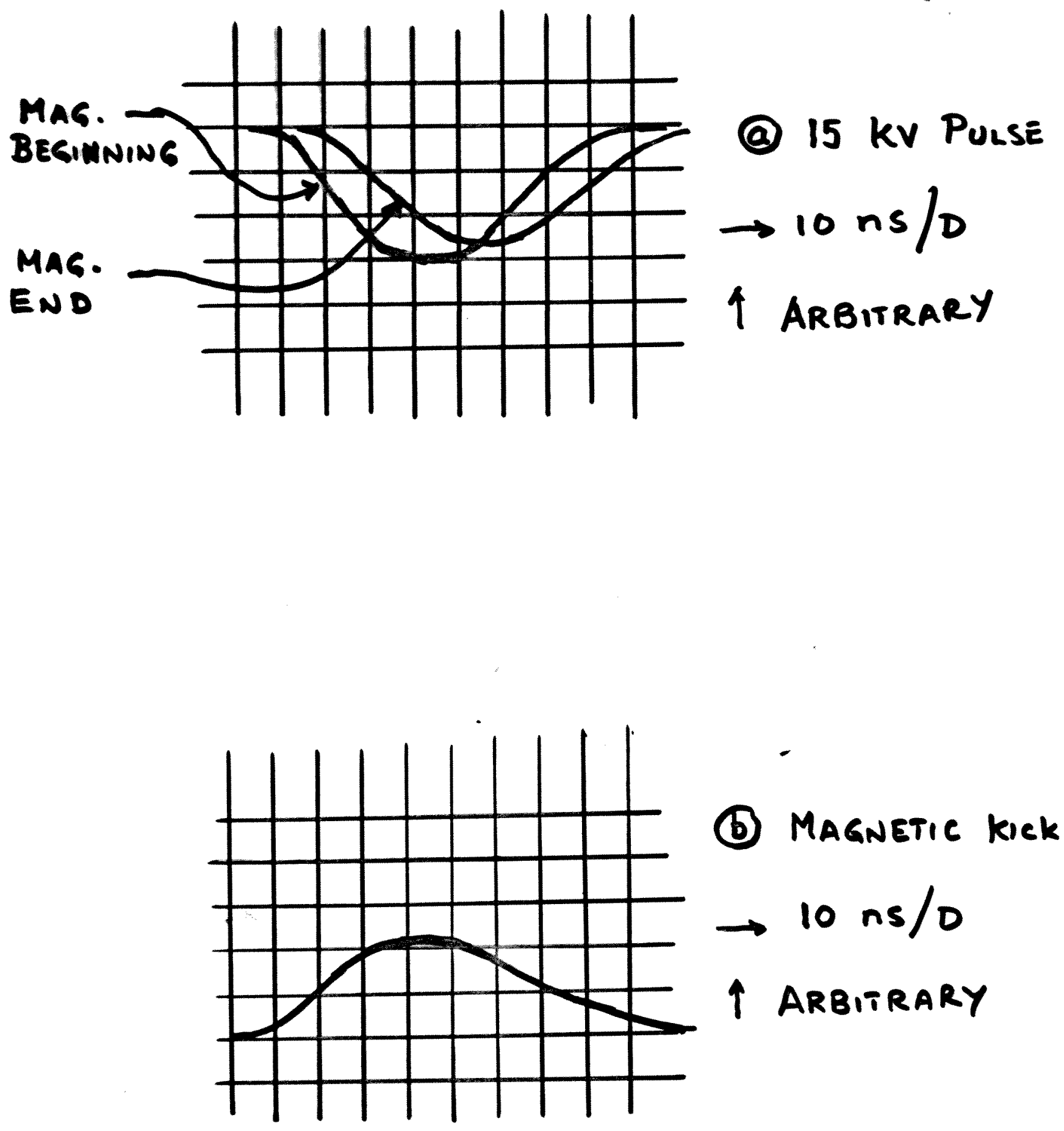

FIG $3: 15$ kV PuLSES, AND KICK 
